\title{
KARAKTERISTIK DAN MOTIVASI WISATAWAN DI OBJEK WISATA AIR TERJUN NYARAI, TAPIAN PUTI, DAN RUMAH POHON DI KECAMATAN LUBUK ALUNG DAN BATANG ANAI
}

\author{
Vivi Yulia Fitri ${ }^{1}$, Ahyuni ${ }^{2}$, Nofrion ${ }^{2}$ \\ Program Studi Pendidikan Geografi \\ Jurusan Geografi Fakultas Ilmu Sosial \\ Universitas Negeri Padang \\ email: viviyuliafitri189@gmail.com
}

\begin{abstract}
ABSTRAK
Penelitian ini bertujuan untuk mengetahui karakteristikwisatawanberdasarkan sosiodemografis, geografis, dan psikologis, dan untuk mengetahui motivasi wisatawan di Objek Wisata Air Terjun Nyarai,Tapian Puti dan Rumah Pohon di Kecamatan Lubuk Alung dan Batang Anai. Jenis penelitian yang digunakan dalam penelitian ini adalah penelitian deskriptif dengan pendekatan kuantitatif. Penelitian ini dilakukan pada bulan Desember 2017- Januari2018. Sumber data sampel sebanyak 136 responden. Teknik pengumpulan data dalam penelitian ini adalah menggunakan wawancara/ angket, pengamatan dan dokumentasi.Teknik analisis data penelitian memakai persentase dan rata-rata.Hasil penelitian menunjukkan karakteristik wisatawan di Objek WisataAir Terjun Nyarai, Tapian Puti dan Rumah Pohon di Kecamatan Lubuk Alung dan Batang Anaidi dominasi oleh laki-laki 61 orang (44.8\%) dan perempuan 46 orang (33.8\%) dengan umur 1725 dengan pekerjaan mahasiswa 80 orang $(58.8 \%)$ dan Berasal dari luar Kecamatan Lubuk Alung. Motivasi wisatawan di Objek Wisata Nyarai, Tapian Puti dan Rumah Pohon adalah berpetualang.
\end{abstract}

Kata Kunci: karakteristik, motivasi, wisatawan

\section{ABSTRACT}

This study aims to determine the characteristics of tourists based on socio-demographic, geographical, and psychological, and to determine the motivation of tourists in Nyarai Waterfall, Tapian Puti and Tree House tourism objects in Lubuk Alung and Batang Anai Districts.The type of research used in this study is descriptive research with a quantitative approach. This research was conducted in December 2017-January2018. Sample data sources were 136 respondents. Data collection techniques in this study are using interviews / questionnaires, observations and documentation. Research data analysis techniques use percentages and averages. The results showed that the characteristics of tourist in Nyarai Waterfall, Tapian Puti and Tree House tourism objects in Lubuk Alung and Batang Anai Districts were dominated by men 61 people (44.8\%) and women 46 people (33.8\%) aged 17-25 with 80 students (58.8\%) and Fromoutside the sub-district.Motivation of tourists in Nyarai Tourism Object, Tapian Puti and Tree House is adventure.

Keyword: Characteristics, Motivation, Tourist

\footnotetext{
${ }^{1}$ Mahasiswa Program Studi Pendidikan Geografi

${ }^{2}$ Dosen Jurusan Geografi Fakultas Ilmu Sosial Universitas Negeri Padang dengan Pembimbing I

Ahyuni dan Pembimbing II Nofrion
} 


\section{PENDAHULUAN}

Pariwisata mempunyai peranan yang sangat penting dalam meningkatkan taraf kehidupan masyarakat, salah satunya bisa dilihat dari segi sosial yaitu bisa menjembatani jarak dan menghilangkan perbedaan-perbedaan, sehingga mampu memupuk rasa persaudaraan antara suku, ras dan agama.

Sumatera Barat merupakan salah satu wilayah yang kaya akan potensi alam terutama di bidang wisata, berupa wisata alam, budaya maupun sejarah. Sumatera Barat menjadi pilihan wisatawan kerena memiliki alam yang sangat indah. Wisatawan yang datang ke Sumatera Barat biasa memilih untuk menjelajahi alam Sumatera Barat.

Salah satu stategi yang dilakukan adalah memanfaatkan kondisi bentangan alam yang ada. Dengan kondisi bentangan alam yang beragam Sumatera Barat memiliki potensi dalam pengembangan pariwisata. Tidak heran bahwa salah satu strategi pembangunan yang di lakukan oleh Provinsi Sumatera Barat adalah mengembangan berbagai macam objek wisata di seluruh bagian wilayah dan mengadakan kegiatan-kegiatan tertentu untuk memperkenalkan sumatera barat ke dunia (Ahyuni, 2015).

Sebagai bahagian dari Provinsi Sumatera Barat Kabupaten Padang Pariaman yang memiliki banyak daya tarik untuk dikunjungi. Sebagai salah satu sasaran wisatawan dalam berwisata yaitu Kabupaten Padang Pariaman yang terletak tidak jauh dari pusat kota Padang.

Beberapa objek wisata yang cukup terkenal di Kabupaten Padang Pariaman adalah 1) Air Terjun Nyarai yang terletak di Korong Gamaran Nagari Salibutan Kecamatan Lubuk Alung, 2) Tapian Puti yang terletak di Korong Sikabu Nagari Sikabu Kecamatan Lubuk Alung, dan 3) Rumah Pohon yang terletak di Sungai Buluah Timur Kecamatan Batang Anai. Diantara tiga objek wisata tersebut, masih ada yang kurang dikenal. Hal ini disebabkan karena sebahagian dari objek wisata yang ada hanya dikelola oleh masyarakat sekitar.

Undang-undang Nomor 10 tahun 2009, menyebutkan pariwisata adalah segala sesuatu yang berhubungan dengan wisata, termasuk pengusahaan objek dan daya tarik wisata serta usaha-usaha yang berhubungan dengan penyelenggaraan pariwisata, dengan demikian pariwisata meliputi:

a. Semua kegiatan yang berhubungan dengan perjalanan wisata.

b. Pengusahaan objek dan daya tarik wisata seperti: kawasan wisata, Taman rekreasi, kawasan peninggalan sejarah, museum, pagelaran seni budaya, tata kehidupan masyarakat atau yang bersifat alamiah: keindahan alam, gunung berapi, danau, pantai.

c. Pengusahaan jasa dan sarana pariwisata yaitu: usaha jasa pariwisata (biro perjalanan wisata, agen perjalanan wisata, konvensi, perjalanan insentif dan pameran, konsultan pariwisata, informasi pariwisata). Usaha sarana pariwisata yang terdiri dari akomodasi, rumah makan, bar, angkutan wisata.

Wisatawan merupakan unsur utama dalam pariwisata. Unsur lain adalah obyek wisata dan sarana serta prasarana periwisata. Terlaksananya kegiatan pariwisata tergantung pada adanya interaksi antara wisatawan dan obyek wisata, yang didukung dengan berbagai sarana dan prasarana pariwisata. Ketiga 
faktor itu saling mempengaruhi sebuah obyek wisata dikatakan menarik jika banyak dikunjungi wisatawan. Sebaik apapun suatu obyek wisata, jika tidak ada yang mengunjungi, tidak akan dikatakan menarik perhatian wisatawan.

Pelaku perjalanan akan disebut wisatawan ketika mereka melakukan kegiatan wisata atau kegiatan yang bersifat rekreatif untuk menikmati suatu obyek wisata. Meskipun melakukan perjalanan, jika tidak bersifat rekreatif maka pelaku perjalanan tersebut tidak disebut wisatawan. Interaksi atara wisatawan dengan obyek wisata akan menjadi lebih intensif dan lebih mudah jika di dukung adanya sarana dan prasarana pariwisata sehingga wisatawan merasa lebih nyaman dan lebih senang dalam menikmati obyek wisata.( Wardiyanta,2006:55-56).

Wisatawan juga dapat dilihat dari sisi geografis, misalnya mengenai tempat asal mereka. Masalah tempat tinggal wisatawan memiliki pengaruh yang signifikan terhadap pemahaman dan intensitas kegiatan wisata seseorang, selain juga terhadap pilihan obyek wisata. Semakin jauh tempat tinggal seseorang dengan tujuan wisata, akan semakin rendah tingkat pemahaman dan intensitas kegiatan wisata yang dilaksanakan. Domisili seseorang juga akan mempengaruhi budaya dan ekspektasi ketika melaksanakan kegiatan wisata karena antara tempat tinggal dan budaya memiliki keterkaitan yanga sangat erat. Faktor lainnya yang turut berpengaruh terhadap pilihan tujuan wisata adalah usia wisatawan, jenis kelamin wisatawan, kondisi sosial wisatawan dan lain-lain (Wardiyanta,2006:56-57).

Gambaran mengenai wisatawan biasanya dibedakan berdasarkan karakteristik perjalanan (trip descriptor) dan karakteristik wisatawannya(tourist descriptor) .

Penelitian Hayani (2007) yang berjudul Motivasi Kunjungan Wisatawan Taman Nasional Gunung Gede Pangrango di Cibodas, mengemukakan permasalahan tentang motivasi pengunjung yang dianggap penting terhadap kemajuan objek wisata Taman Nasional Gunung Gede, serta penghambat kunjungan wisatawan untung datang ke objek Wisata Taman Nasional Gunung Gede.

Penelitian Fatimah (2014), yang berjudul Persepsi Pengunjung Tentang Fasilitas Wisata Di Objek Wisata Lembah Harau Kabupaten Lima Puluh Kota, mengemukakan tentang fasilitas yang ditawarkan di objek wisata Lembah Harau, serta pembenahan terhadap fasilitas yang ada di objek wisata Lembah Harau.

Berdasarkan observasi awal dan kajian teori yang dilakukan terdapat bahwa jumlah pengunjung pada hari libur lebih banyak dari pada hari biasa. Data ini didapat dari hasil wawancara peneliti dengan pengelola objek wisata tersebut. Melihat jumlah wisatawan tersebut maka peneliti ingin mengetahui apa yang memotivasi wisatawan untuk untuk berkunjung ke suatu ojek wisata. Untuk itu peneliti akan meneliti dengan judul "Karakteristik dan Motivasi Wisatawan yang Datang Berkunjung ke Objek Wisata Air Terjun Nyarai,Tapian Puti dan Rumah Pohon Di Kecamatan Lubuk Alung dan Batang Anai.”

\section{METODE PENELITIAN}

Jenis penelitian yang digunakan dalam penelitian ini adalah penelitian deskriptif dengan pendekatan kuantitatif. Penelitian ini akan dilakukan pada bulan OktoberNovember 2017, di Objek Wisata Lubuk Alung dan Batang Anai yang terdiri dari 3 
objek wisata yaitu Nyarai, Tapian Puti, dan Rumah Pohon. Populasi penelitian ini adalah seluruh pengunjung di Objek Wisata Lubuk Alung dan Batang Anai. Data dalam penelitian ini termasuk dalam klasifikasi respons tertulis. Respon tertulis diberikan atas pertanyaan tertulis (angket) yang diajukan oleh peneliti. Teknik pengumpulan data dalam penelitian ini adalah wawancara, pengamatan, dan dokumentasi. Instrumen penelitian yang digunakan untuk mengukur variabel dalam rangka mengumpulkan data adalah angket. Teknik analisis data dalam penelitian ini dilakuan dengan cara rumus presentase dengan mendeskripsikan data yang sudah didapat.

\section{HASIL PENELITIAN}

\section{Karakteristik Wisatawan}

\section{Karakteristik Wisatawan Menurut Sosiodemografis}

Berdasarkan

karakteristik

Sosiodemografi dari wisatawan yang berkungjung ke objek wisata di Kecamatan Lubuk Alung Dan Batang Anai ini, mulai dari Nyarai, Tapian Puti dan Rumah Pohon dapat dilihat dari berbagai sisi mulai dari banyak kunjungan, umur, status, pendidikan, pekerjaan dan jumlah keluarga.

Berdasarkan penjelasan mengenai karakteristik wisatawan menurut Sosiodemografis dengan indikatorindikator yang telah dijelaskan diatas maka dapat disimpulkan pengunjung objek wisata di Kecamatan Lubuk Alung dan Batang Anai mulai dari Nyarai, Tapian Puti dan Rumah Pohonbanyak didominasi oleh laki-laki dengan umur 18-22 tahun dan banyak yang masih belum menikah. Para pengunjung objek wisata tersebut rata-rata banyak yang tingkat pendidikannya perguruan tinggi denganjenis pekerjaanmahasiswa, dan dengan jumlah anggota keluarga sebanyak 5 orang.

\section{Karakteristik Wisatawan Menurut Geografis}

Karakteristik wisatawan menurut Geografis berkunjung ke objek wisata di Kecamatan Lubuk Alung dan Batang Anai ini, mulai dari Nyarai, Tapian Puti dan Rumah Pohon dapat dilihat dari berbagai sisi mulai dari alamat, daerah asal serta pola perjalanan.

Berdasarkan penjelasan mengenai karakteristik wisatawan menurut geografis dengan indikator-indikator yang telah dijelaskan diatas maka dapat disimpulkan pengunjung objek wisata di Kecamatan Lubuk Alung dan Batang Anai mulai dari Nyarai, Tapian Puti dan Rumah Pohonbanyak di dominasi oleh pengujung yang berasal dari luar Kecamatan Lubuk Alung, sedangkan pola perjalanan wisatawan yang berkunjung ke objek wisata tersebut mereka banyak melakukan pola perjalanan dari Padang ke Lubuk Alung.

\section{Karakteristik Wisatawan Menurut Psikografis}

Karakteristik wisatawan menurut Psikografis yang berkungjung ke objek wisata di Kecamatan Lubuk Alung dan Batang Anai mulai dari Nyarai, Tapian Puti dan Rumah Pohon dilihat dari beberapa indikator seperti dengan siapa wisatawan berkunjung, lama kunjungan, informasi objek wisata, kunjungan objek wisata, penginapan, transportasi, minat untuk datang kembali, kegiatan yang dilakukan selama berada di objek wisata, sarana, prasarana, ketertarikan pengunjung terhadap objek wisata, kondisi objek 
wisata serta kepuasan wisatawan yang berkunjung.

Berdasarkan penjelasan mengenai karakteristik wisatawan menurut psikografis dengan indikator- indikator yang telah dijelaskan diatas maka dapat disimpulkan pengunjung objek wisata di Kecamatan Lubuk Alung dan Batang Anai mulai dari Nyarai, Tapian Puti dan Rumah Pohonpada umumnya mereka banyak berkunjung dengan teman dengan waktu kunjungan ditempat objek wisata selama 1-2 jam. Sumber informasi yang diperoleh wisatawan mengenai objek wisata kebanyakan dari teman yang pada umumnya para pengunjung baru satu kali kesana.Umumnya para pengunjung tidak menginap.Adapun transportasi yang digunakan pengunjung menuju objek wisata disana menggunakan sepeda motor.Mengenai sarana dan prasarana yang ada di objek wisata sudah cukup.Para pengunjung disana banyak yang tertarik pada panorama alamnya yang alami.Dilihat dari kondisi kebersihan objek wisata sudah dikatakan cukup bersih dengan perasaan pengunjung memuaskan untuk berkunjung ke objek wisata tersebut.

\section{Motivasi Wisatawan}

Mengulas hasil tabel dari pengolahan data yang dilakukan, dapat terlihat motivasi wisatawan terhadap objek wisata di Kecamatan Lubuk Alung dan Batang Anaiuntuk wisatawan yang menjawab berlibur menjawab berlibur sebanyak 36 orang (40\%), di Tapian Puti sebanyak 16 orang (41\%). Selanjut nya untuk wisatawan yang menjawab berpetualang 36 orang (40\%), di Tapian Puti 6 orang (16\%), dan di Rumah Pohon sebanyak 3 orang (60\%). Selanjutnya yang menjawab pergi rekreasi di Nyarai sebanyak 13 orang (14\%), di Tapian Puti sebanyak 11 orang (28\%) dan di Rumah Pohon sebanyak 2 orang (40\%). Selanjutnya yang menjawab kesenangan di Nyarai sebanyak 7 orang (8\%), di Tapian Puti sebanyak 6 orang (15\%).

Berdasarkan tabel dan penjelasan diatas mengenai motivasi wisatawan terhadap objek wisata di Kecamatan Lubuk Alung dan Batang Anai mulai dari Nyarai, Tapian Puti dan Rumah Pohon umum nya banyak yang menjawab berlibur. Hal ini terbukti dari 136 jumlah pengunjung 52 diantaranya (38\%)banyak yang menjawab motivasi mereka untuk datang ke objek wisata tersebut adalah untuk berpetualang .

Dilihat dari karakteristik dan motivasi wisatawan yang berkunjung ke objek wisata di Kecamatan Lubuk Alung Dan Batang Anai ini, mulai dari Nyarai,Tapian Puti dan Rumah Pohon dapat dilihat dari berbagai sisi maka objek wisata Nyarai,Tapian Puti, dan Rumah Pohon di kategotikan sebagai Objek wisata Minat Khusus, hal ini sejalan dengan yang dikatakan oleh(Fandeli, 2002: 107108 dalamFatimah, Alip 2017 )

\section{KESIMPULAN DAN SARAN}

Kesimpulan

Berdasarkan hasil penelitian dan pembahasan yang telah dilakukanyang berkunjung ke objek wisata di Kecamatan Lubuk Alung dan Batang Anai Untuk Objek wisata Nyarai jumlah laki-laki sebanyak 53 orang $(58 \%)$ dan perempuan sebanyak 39 orang (42\%). Untuk objek wisata Tapian Puti jumlah laki-laki sebanyak 23 orang (59\%) dan perempuan 16 orang (41\%).Sedangkan untuk objek wisata Rumah Pohon jumlah laki-laki 2 orang (40\%) dan perempuan 3 orang $(60 \%)$. 


\begin{abstract}
Sedangkan karakteristik wisatawan menurut sosio-demografis dengan indikator-indikator yang telah dijelaskan diatas maka dapat disimpulkan pengunjung objek wisata di Kecamatan Lubuk Alung dan Batang Anai Mulai dari Nyarai, Tapian Puti dan Rumah Pohon banyak didominasi oleh laki-laki dengan umur 18-22 tahun dan banyak yang masih belum menikah. Para pengunjung objek wisata tersebut rata-rata banyak yang tingkat pendidikannya tamatan perguruan tinggi dengan pekerjaan para pengunjung umumnya yang datang adalah mahasiswa dan dengan jumlah anggota keluarga sebanyak 5 orang.Motivasi nwisatawan terhadap objek wisata di Kecamatan Lubuk Alung dan Batang Anai Mulai dari Nyarai, Tapian Puti dan Rumah Pohonumumnya banyak yang menjawab berpetualang.

Dilihat dari karakteristik dan motivasi wisatawan yang berkunjung ke objek wisata di Kecamatan Lubuk Alung Dan Batang Anai ini, mulai dari Nyarai,Tapian Puti dan Rumah Pohon dapat dilihat dari berbagai sisi maka objek wisata Nyarai,Tapian Puti, dan Rumah Pohon di kategotikan sebagai Objek wisata Minat Khusus.
\end{abstract}

\section{Saran}

1. Untuk leih menariknya objek-objek wisata perlu pembenahan akses jalan sarana umun seperti wc, mushola dan dibangun tempat istirahat bagi wisatawan

2. Bagi warga setempat agar bisa memberikan pelayanan yang ramah kepada para pengunjung objek wisata agar menarik wisatawan untuk datang

\section{DAFTAR PUSTAKA}

Arikunto,Suharsimi.2010.Menejemen Penelitian.Jakarta:Rineke Cipta

Ahyuni dan Sri Mariya.2015.Minat

Wisatawan Asing Berkunujung Ke

Objek Wisata di Wilayah Bagian

Selatan Provinsi Sumatera Barat.

Jurnal Geografi Vol.4. Page 200-

212. diambil dari

(http://repository.unp.ac.id/id/eprint/1

6027) (29 agustus 2018)

Fatimah. 2014. Persepsi Pengunjung

Tentang Fasilitas Wisata Di Objek

Wisata Lembah Harau Kabupaten

Lima Puluh Kota.Skripsi

Fatimah, Alip. 2017. Potensi Wisata Minat

Khusus Di Jalur Pendakian

Sapuangin Taman Nasional Gunung

Merapi, Tegalmulyo, Kemalang,

Klaten. Skripsi

Hayani , 2007. Motivasi Kunjungan

Wisatawan Taman Nasional Gunung

Gede Pangrango di Cibodas.Skripsi

Pratama, Axel Christine.dkk. 2016.

Karakteristik, Motivasi Dan Aktivitas

Wisatawan AsiaDi Kelurahan Ubud.

Skripsi Fakultas Pariwisata Unud

Rachman, Arief F Dkk.2013.Pemandu

Wisata : Teori Dan Praktek. Jakarta :

Media Bangsa

Sugiyono. 2010. Statistika Untuk

Penelitian. Bandung: Alfabeta.

Suparmoko. 1997. metode penelitian praktis (untuk ilmu-ilmu sosial ekonomi). Yogyakarta: BPFE

Suwanto, Gamal. 2004. Dasar-Dasar Pariwisata.Yogyakarta : Andi

Undang-undang No 10 tahun 2009 tentang pariwisata

Wardianta. 2006. Metode Penelitian Pariwisata. Yogyakarta: Andi 